\title{
Investigation of the Interactive Positive Processes of Couples with Different Characteristics: A Qualitative Study
}

\author{
Zahra Chabokinejad $^{1}$, Ozra Etemadi $^{2}$, Fatemeh Bahrami ${ }^{3} \&$ Maryam Fatehizadeh $^{4}$ \\ ${ }^{1}$ PhD Students, Department of Counseling, Faculty of Education and Psychology, University of Isfahan, Isfahan, \\ Iran \\ ${ }^{2}$ Associate Professor, Department of Counseling, Faculty of Education and Psychology, University of Isfahan, \\ Isfahan, Iran \\ ${ }^{3}$ Professor, Department of Counseling, Faculty of Education and Psychology, University of Isfahan, Isfahan, Iran \\ ${ }^{4}$ Associate Professor, Department of Counseling, Faculty of Education and Psychology, University of Isfahan, \\ Isfahan, Iran \\ Correspondence: Ozra Etemadi, Department of Counseling, Faculty of Education and Psychology, University of \\ Isfahan, Isfahan, Iran. E-mail: O.etemadi@edu.ui.ac.ir
}

Received: February 16, 2015

Accepted: February 28, 2015

Online Published: April 28, 2016

doi:10.5539/mas.v10n7p49

URL: http://dx.doi.org/10.5539/mas.v10n7p49

\begin{abstract}
Interactive processes encompass all those aspects of interpersonal and intrapersonal processes that affect the communication loop of couples. This study aims to test positive interactive processes among couples with different personality traits. In order to collect data, twenty psychotherapists specializing in couples' therapy and forty eight couples of different personality traits referred to counseling centers of Yazd city were selected (using purposeful sampling). Semi-structured interviews were conducted and the procedure continued up to data saturation. Additionally, books, articles and Internet sites were additionally used for data collection. The research method of qualitative content analysis was conducted. positive test results obtained from the interactive processes between couples with different personality traits can be categorized into the open-ended codes of (levels of give and take, emotional control, Improve cognition, cognitive processing control, Efficient behaviors, planning, accountability, financial management and household) along with the four major codes of "cognitive, emotional, behavioral, and managerial" skills. Differences in personality traits can be traced to all mental, behavioral and functional dimensions of couples and can also influence the total level of communication between the couples. Therefore, taking these differences into account and learning how to manage them can reduce conflicts over such differences.
\end{abstract}

Keywords: positive interactive processes, different personality traits, couples

\section{Introduction}

Marital relationship is the process by which husband and wife verbally and non-verbally interact through listening, pause, facial expressions and gestures with each other in order to share their feelings and thoughts. Couples interact through various channels with each other. Those communication channels that frequently occur in a family are called the communication pattern (Rasouli, 2001). Marital relationship is a process of information exchange as verbal and nonverbal skills among couples within the system of married life (Gladding, 2003).

Verbal communication: vocal behavior (verbal communication), includes all aspects of the speech, such as the language and its verbal tools. For instance, tone, rate, stress, and so on. When a person communicates with another person through language, a relationship forms between them non-existent in other parts of nature (Hargie et al., 1994).

Non-verbal communication: verbal messages make up merely a small portion of interpersonal communications that are sent using words and sentences, usually associated with rich nonverbal signs which support, modify, or even completely change the verbal message (Forgas \& Jones, 2000). Mehrabian (1968) analyzed messages sent in an interpersonal communication between the individuals and found that only 70 percent of meanings were conveyed to the audience through verbal messages. Ninety three percent of non-verbal messages that are sent non-verbally are divisible into the following: thirty eight percent vocally and fifty five percent facially. Though 
findings of the various studies differ, it can be concluded that non-verbal cues are very important in interpersonal communication and its role is crucial in many instances that transfer meaning from one person to another (Farhangi, 2006).

Other alternatives are the use of non-verbal messages only. Non-verbal communication as a communication system compared to the language includes very different characteristics decoding and responding to nonverbal messages in reaction to verbal messages is much faster and more automated. When a party during interacting with you, smiles, stares, or winks at you, you do not hesitate to interpret and react to the signals. In contrast, for understanding, interpreting and preparing a response to a verbal message much more time needs to be spent.

As a result, non-verbal cues can often evidently reveal the speaker of the attitudes, feelings and emotions that they might be reluctant to reveal (Forgas \& Jones, 1985). A person's behavior, facial expressions, gestures, posture, and other actions, uninterrupted flow of information and stable source of symptoms can be related to emotions that he experiences. Non-verbal signs, not only portray one's feelings, but also show how he comes along with your emotions (Bolton, 2005).

People should be able to properly understand the views of others and try to understand all the messages. They should note that all meaning of the messages are not in the words that are uttered. Another important aspect of effective communication is non-verbal messages. They should try in a way that their verbal messages agree with their non-verbal messages. People must know themselves and monitor their performance and attempt to do what they say and say what they do. Their reward in this way, will be achieving their goals more easily and satisfaction with their relationships with others (Sandra et al., 1991).

The need for intimacy as growth, maturity and maturation, differentiation and enhanced expression of global biological need for physical proximity, communication and contact with other people can be conceptualized as the overall intensity of devotion to individual needs and different from others. People are different with regard to individual differences in the severity and type of intimacy with each other. Research has shown that between similarity of personality traits among couples and marital intimacy there exists a significant positive correlation (Jaberi, 2013).

Marriage is one of the most important areas of life into which many factors are involved. Clear expression of needs and feelings, refraining from insult, avoiding blaming, using feedback, paying attention to non-verbal signs, avoiding burble and trying to understand are among the factors that affect the success of couples in marital relationships (Young \& Lang, 1998).

Parvin(1989) suggests that there is general agreement that personality traits play an important role in the outcome, positive or negative, and character reflects those of the individual characteristics that are of the fixed pattern of behavior (quoted in Javadi \& Kadivar, 1998). Houston's (2000) maintains that on the basis of personality, one can predict how they react in different situations. Characters, as a factor, directly influences the communication process that affects couples' marital satisfaction. Character of an individual calls various reactions from the other side which, in toto, is effective in their satisfaction.

Botwin et al (1997) believe that given the importance of marital satisfaction in the performance of husband and wife, children, family and society, personality factors and personal factors in the family are among the factors that can predict marital satisfaction. Stroud (2010) shows that although efforts have failed in a complete portrayal of different aspects of marital satisfaction, marital satisfaction can be perceived more clearly within certain aspects of married life. Displaying problematic areas have helped to the understanding of the causes of consent and marital satisfaction. Zoby (2005) states that the issue has been considered by experts in the family and marriage satisfaction and quality necessary to identify the factors lowering the couples' marital problems. Its application is to prevent such marriages. Research on personality traits as one of the most important requirements in the marriage, a long history in predicting marital satisfaction and marital harmony by two individuals with their own personality traits upon which their marriage is determined.

Botwin et al (1997) point out that people tend to select their romantic partners based on similarities in some of the attributes of their choice. Based on this knowledge, psychologists have examined whether people are more attracted to people like themselves and even whether the espouses become more similar over time or not? Donnellan et al (2007) stated in a research on marriage based on the similarity or assimilation, that couples tend to show a range of factors including demographic characteristics and attitude. Another question that arises is whether couples have more successful relationships with characters alike? Review of the literature suggests that the empirical evidence on this issue is sporadic. On the one hand, several studies have reported that a similar figure is a significant predictor of marital satisfaction and on the other hand, several studies have found no relationship between the couple's similar character and their relationship. 
Charania (2007) in his study showed that the character has an effect on marital satisfaction. Results showed a significant effect for openness, accountability, consistency, attachment anxiety, negative gravity and the socio-sexual features.

Researchof Gur-Aryeh (2010) examined the association between emotional instrumentation, gender and uniqueness in character as predictors of marital satisfaction. It shows that positive emotions for women is more predictive of extraversion than men. Also extraversion analysis revealed that it was positively and significantly associated with positive emotional tools and that wives were similar in extraversion than spouses who reported lower marital satisfaction level was dissimilar their extroversion.

Drinforth (2010), in a large sample of married couples in the United Kingdom and Australia, studied the effects of the individual and the individual character of relationship satisfaction and overall life satisfaction. It showed that personality has an impact on life satisfaction of all. O'Rourke et al (2011) examined the predictive character and found that higher levels of extraversion in couples for marital satisfaction is higher for women and men as well as similarities predicted marital satisfaction of spouses at a high level of experiential and agreeable levels.

O,rak and colleagues (2011) showed that the similarity between couples with marital satisfaction and relationship stability are dependent on the concept of generalization. It is assumed that personality similarity between spouses also predicted marital satisfaction. Creswell and Waltz (2002) Croyle \& Waltz (2002) showed that the similarity between couples might be an important variable in predicting marital satisfaction.

Rasti (2003) in a study to examine the relationship between personality traits and marital satisfaction, based on the five-factor model of the 50 couples of married students took the scale of the NEO Five Enrich Marital Satisfaction. The test results showed that five factors of agreeableness, neuroticism, conscientiousness, extraversion and flexibility significantly predicted marital satisfaction. Women score higher in neuroticism and openness and lower in extraversion and marital satisfaction.

Olia, et al (2006) showed that intimate relationships among couples require attention to issues such as communication skills and the ability to notice what the espouse had experienced, being empathic and sensitive in addition to being aware of the needs.

Etemadi et al (2006) studied the combination of the concept of intimacy and ways to boost it. In this model, problem solving skills (including identifying problems and solving them, training constructive ways to solve problems) and communication skills were mentioned to enhance the intimacy of couples and solve the problems of the intimacy.

Etemadi et al (2006) investigated the effectiveness of cognitive-behavioral therapy on intimacy of spouses examined. The results show that the use of problem-solving techniques based on cognitive-behavioral theory of general intimacy, emotional and sexual intimacy has increased. Most scholars have neglected of factors such as the characteristics and personality traits that are sustainable in the long term and affect the marital satisfaction of couples. Therefore, it is necessary to comment on the causes of the individual pathological marital disagreements and lack of success in marriage and the role of personality factors that are examined in the intimacy and marital conflicts. This study seeks to explore the positive interaction processes of couples whose personality characteristics are different.

\section{Method}

This research is a qualitative research with a content analysis as its approach. Content analysis is a valuable place in the realm of research and a good tool for qualitative researchers (Kripenof, 2004).

The content of documents to extract the main themes and patterns that are present in the data is analyzed. The transcript is reviewed several times to the smallest parts and the meaningful parts (theme or subject matter) are broken. A list of themes is provided. The words are so similar in meaning that reviewing them would be clear. They are open to review by focusing on the themes of which will be placed in a sub-category. In order to collect data 20 psychotherapist specializing in couples therapy and forty eight couples features a different personality referred to counseling centers Yazd city with purposive sampling (according to qualitative research) interviews were semi-structured. The first interview by asking general questions and then gradually deepening confidence couple of questions addressed. This type of interview because of the flexibility of being fit and in-depth qualitative research. As well as books and articles, and Internet sites also were used to collect data.

Questions interviews of couples with different personality characteristics of the sample:

1. What is your relationship with your spouse?

2. What is negative in your relationship? 
4. Which does not meet the demands and needs of you through your marriage?

5. How do you see your partner in a couple relationships?

Therapists interview question:

Couples with different personality traits or negatives in the relationship and interactions happen? What are their coping strategies?

All conversations on audio tape recorded and transcribed verbatim and analyzed were handwritten. During the research process, from data collection to analysis and report the findings include: informed consent, maintaining anonymity, confidentiality, right to withdraw at any time, the provisions of the moral obligations were not met.

Demographic information such as age, education, length of marriage as well as questions were raised about the interactive process, interviews were conducted in individual counseling sessions. Interviews are necessary to achieve the so-called rich, saturated other information or content theme continues new data is added. On this basis, forty eight couples with different personality traits that go to counseling centers in Yazd city had to get duplicate data have been interviewed. Inclusion criteria for healthy couples (lack of personality disorder or severe clinical disorder so as to interfere in the interview process and the history information by interviewing clients), to participate in counseling or treatment programs at the same time, do not receive the psychiatric drugs and drug and alcohol abuse by the diagnostic interview and direct questions of people examined.

The study fits with qualitative research, real and natural environment and all interviews were conducted by researchers at the counseling centers of Yazd city Validity and reliability of data acceptance criteria and terms of qualitative research will be described and labeled determine, acceptable means of data and it also depends on the actual data collection. To increase the acceptability of the data of

Table 1. Demographic characteristics of the couples studied

\begin{tabular}{cccc}
\hline Variable name & & Number & Percent \\
\hline Age & $25-30$ & 20 & 41.67 \\
& $30-35$ & 15 & 31.25 \\
& $35-40$ & 13 & 27.08 \\
Education & BS & 30 & 62.5 \\
& Diploma & 18 & 37.5 \\
Duration of marriage & $2-4$ & 20 & 41.67 \\
& $4-6$ & 18 & 58.33 \\
Sum & & 48 & 100 \\
\hline
\end{tabular}

\section{Findings}

Demographic characteristics of the study subjects are shown in Table 1. The hand-written analysis of the interactive positive process in couples with different personality traits, were the following categories which will be detailed in the discussion. Table 2 sets Extracted concepts and categories of the show.

The results include the following concepts: The concept was to include improve in levels (sensation seeking, emotional needs, emotional expression, ease of physical contact, contact with the outside world, itself troughs, emotional responsiveness, understanding the emotional needs of the other side, which is a subset of emotional exchange and then placed at the center of the excitement.

One of the participants in this study about the positive consequences of interactions between couples with different personality traits such notes and says:

"If couples respect each other and understand each other, they can also listen to the words, but when they are sharp or angular speak together are far from discouraged." (Couples, Female)

My husband judged rapidly and without permitting me to defense myself, but after talking about my discomfort he acts much better and attempts to know my idea about matters (Couples, Female).

Harried judgment of couples which initiate from cognitive mistakes could expose their life to some problems and it is one of the anticipating factors for divorce (Therapist).

Fifth concept includes help to (further partnership, proper social behavior adjustment of leisure time, decrease of aggression. Increasing levels of self - acceptance) which is subset of efficient behaviors and places in behavioral 
topic.

((My wife didn't pay any attention to me and most of time notice her problems but when she has known the different personality trails of me and her notice to me and my desires)). (husband).

Participants said that avoiding from breaking and resigning is one of the most important cases which have significant effect on marital interactive process (one of the couples said):

((When I and my husband differ on something we relegate it to another time but we don't break the relation)) (Wife).

In view of Gotman, signs of defeating matrimony and tend to divorce, which accounts as a part of negative interactions and poison the relation, is existence of four aggressive factors in marital interactions. These factors are: (censure, contempt, being defensive and resigning) (Gotman, 1999).

Sixth concept includes improvement of (programming levels, flexibility in program and discipline) which is subset of planning and places in efficient management performance topic.

My husband is a persistent programmer but when we married, he accompanied with me more (wife)

Difference is discipline and flexibility of couples is one of the Factors discontent between couples with different personality traits but when the disordered person supported with his or her spouses that is regular and being inflexible (Therapist).

Seventh concept covering: (duties and rules acceptance, balancing of discipline and resilient) which is subset of responsibility and places in efficient management performance topic.

Different couples could cheer their life with responsibility and amenability to each other (wife).

Spouse who isn't apathetic into his or her home and his or her spouse make affection and fondness and intimacy don't increase in these couple (Therapist).

Researchers believe that couple should know each other's desires and needs. (Yong \& long, 1998)

Next concept of marital positive interactive between couples with different personality traits is improving (equipoise of duties distribution Financial commensurate earnings and expenses, management accordance) which is subset of fanatical and domestic management in place of efficient management performance topic.

My husband is too wastrel but with financial management we haven't any problem (wife).

One of current couple problems is lack of fanatical management (Therapist).

Table 2. Extracted concepts of positive interaction processes couples with different personality traits

\begin{tabular}{|c|c|c|c|}
\hline Implications & Open coding & Axial coding & Nuclear code \\
\hline $\begin{array}{l}\text { 1- Help to } \\
\text { (Sensation seeking, emotional needs, emotional } \\
\text { expression, ease of sexual contact, contact with the } \\
\text { outside world, emotional responsiveness, } \\
\text { understanding the emotional needs of the other } \\
\text { side) }\end{array}$ & $\begin{array}{l}\text { Levels of } \\
\text { exchange }\end{array}$ & Emotion & $\begin{array}{l}\text { Positive interactive } \\
\text { Processes }\end{array}$ \\
\hline $\begin{array}{l}\text { 2- Help to (adjustment of anger, decrease of } \\
\text { impulses proper expression of excitements) }\end{array}$ & $\begin{array}{l}\text { Emotional } \\
\text { control }\end{array}$ & Emotion & $\begin{array}{l}\text { Positive interactive } \\
\text { Processes }\end{array}$ \\
\hline $\begin{array}{l}\text { 3- Help to (seeking more confidence, changing } \\
\text { traditional and stereotyped thoughts. More logical } \\
\text { decision making, balanced risk-taking, modifying } \\
\text { expectative, peace of impression and logic) }\end{array}$ & $\begin{array}{l}\text { improve } \\
\text { cognitions }\end{array}$ & Cognitive & $\begin{array}{l}\text { Positive interactive } \\
\text { Processes }\end{array}$ \\
\hline $\begin{array}{l}\text { 4- Help to improve (logical judgment, adiustment } \\
\text { the high rate of processing. Increasing show } \\
\text { processing. more gently responses to events) }\end{array}$ & $\begin{array}{l}\text { control } \\
\text { processing } \\
\text { Cognitive } \\
\end{array}$ & Cognitive & $\begin{array}{l}\text { Positive interactive } \\
\text { Processes }\end{array}$ \\
\hline $\begin{array}{l}\text { 5- Help to (further partnership, proper social } \\
\text { behavior, adjustment of leisure time, decrease of } \\
\text { aggression increasing levels of self- acceptance) }\end{array}$ & $\begin{array}{l}\text { Efficient } \\
\text { behaviors }\end{array}$ & Behavioural & $\begin{array}{l}\text { Positive interactive } \\
\text { Processes }\end{array}$ \\
\hline $\begin{array}{l}\text { 6. Improvement of (common and adaptive } \\
\text { programming, balancing of discipline and resilient) }\end{array}$ & Planning & $\begin{array}{l}\text { effective } \\
\text { performance }\end{array}$ & $\begin{array}{l}\text { Positive interactive } \\
\text { Processes }\end{array}$ \\
\hline
\end{tabular}




\begin{tabular}{llll}
\hline & & management & \\
\hline $\begin{array}{l}\text { 7. Improvement of (duties and rules acceptance, } \\
\text { equilibrium between conditioning and simplifying) }\end{array}$ & Accountability & $\begin{array}{l}\text { effective } \\
\text { performance } \\
\text { management }\end{array}$ & $\begin{array}{l}\text { Positive interactive } \\
\text { Processes }\end{array}$ \\
\hline $\begin{array}{l}\text { 8. Improvement of (equipoise of duties distribution, } \\
\begin{array}{l}\text { Financial earnings and expenses, management } \\
\text { accordance) }\end{array}\end{array}$ & $\begin{array}{l}\text { Financial } \\
\text { management } \\
\text { and household }\end{array}$ & $\begin{array}{l}\text { effective } \\
\text { performance } \\
\text { management }\end{array}$ & $\begin{array}{l}\text { Positive interactive } \\
\text { Processes }\end{array}$ \\
\hline
\end{tabular}

\section{Discussion}

One of the most effective factors on marital interactive process is communication skills which are emphasized by couple in most of interviews. Self and spouse cognition and accepting individual personality and sexuality differences could be effective on marital satisfaction and martial success. According to research findings intimate relations of couple need relational skills such as notice to subject on their spouse point of view and sympathetically understanding of what their spouse experienced and also be aware and sensitive to his or her needs (Olia and et al, 2006).

The study present a fusion model for conceptualizing intimacy and methods of it's increasing. In the model skill of problem solving (include: finding problems and methods of their solving, education and practice of beneficial methods for solving problems) mentioned as one of the rational skills which is necessary for couple intimacy and solve problems of intimacy (Etemadi, 2006).

Different factors have role on marital relations which is one of the most important realms of individual's life. Clear expression of needs and feelings, avoidance from contempt, avoidance from loaming, use from feedback, note to body language signs, avoidance from logorrhea and attempt to understand the spouse viewpoint are effective factors in couple success (Young and Long, 1998).

Couples think that how the problem solving is important on quality of marital relation. The other finding is also accepting the matter that in the study present a fusion model for conceptualizing intimacy and methods of its increasing. In the model skill of problem solving (include: finding problems and methods of their solving, education and practice of beneficial methods for solving problems) mentioned as one of the rational skills which is necessary for couple intimacy and solve problems of intimacy (Etemadi, 2006).

Different factors have role on marital relations which is one of the most important realms of individual's life. Clear expression of needs and feelings, avoid from contempt, avoidance from blaming use from feedback, note to body language signs, avoidance from logorrhea and attempt to understand the spouse viewpoint are effective factors for couple success (Yong and Long, 1998).

Likewise in examining the role of personality anticipating on marital satisfaction and it was found that higher levels of extraversion of couple have higher marital satisfaction in both men and women and also spouse similarities in empiricism and adaptability related to higher marital satisfaction (Orourke et al, 2011). Obviating the needs include disregarding to spouse needs and sexual needs. Intimate relations of couple need relation skills such as notice to subject on their spouse point of view and sympathetically understanding of what their spouse experience and also be aware and sensitive to his or her needs (Olia et al, 2006).

In the study the effect of behavioral - cognitive couple therapy is examined on spouse intimacy. Results of the study show that use of problem solving and techniques of behavioral- cognitive theory increase total intimacy, affective and sexual intimacy. (Etemadi et al, 2006). One of the subjects which was noticed by family and marriage specialists was recognizing decreasing factors of consent and quality of marital relation in problematic couple and applying that for preventing from such marriages. One of the most important properties in marital and marriage studies is research on personality trails. It has a long history in predication of marital satisfaction and marital congruity by personality traits that the two persons being with themselves into the marriage. (Zoby. 2005).

Researchers believe that people tend to choose their romantic spouses according to similarities in some traits According to this knowledge. Psychologists studied that whether people further absorb on similar during time or not? (Botwin et al, 1997). Researches on choosing spouse according to similarities or assimilionism show that couples tend to have similarities in some factors such as demographic characteristic and observational realm. (Donnellan et al, 2007). Most researchers have ignored factors such as personal traits and characteristics which in long- term and more constantly influence couples satisfaction from marital life. Thus, the present research tries to find positive interactive processes of couples which they have different personality traits. A researcher in 
his search demonstrated that personality influence on martial satisfaction (Charnia, 2007). In studying the relation between emotional instrumentation, sex and syncretism in personality for predicting martial satisfaction, which it was shown instrumentation in positive emotions for women was more predictive than men for extroversion (Gur- Aryeh, 2010). In a big sample of married couples in England and Australia for studying effects of intrapersonal and interpersonal personality on marital and whole life satisfaction was demonstrated that personality influenced on whole life satisfaction (Dyrenforth, 2010).

\section{Conclusion}

Personality traits have an important role on communications and marital interaction. Couples with similar personality traits are more successful and have more adaptability than couples with different personality traits. In view point of marital positive interactive processes in couples with different personality traits in emotional dimension and in levels of emotional give - and - take include improvement in levels of (sensation seeking, affective needs, emotion expression, convenience of somatic torches, more relation with out, introspecting, emotional responding, and understanding emotional needs of addresses.) Couples with different personality traits could increase life satisfaction through better relation and more support from each other. The couple are different in emotion expression, one is high energy and the other is low, one need to show effective and emotion expression and the other is cool But with awareness from this differences they could change them to attraction not disagreement.

Couples with different personality trails could have anticipating behaviors and emotional control if they use less blame and contempt or they don't break the relation and don't behave defensively or when they aren't able to solve their problems don't use verbal or physical aggression. Couples with different beliefs, different criteria for decision making, they all could have negative effect on their interactions and relations and during time these difference will disappoint couple and after while they don't pay any attention to each other's needs and desires and finally will affect on intimacy and adaptation of them couples who have differences in rate of judges rapidly according to immediate thoughts and the other judges slowly and with delay. The difference could influence on their interactions. For example, in couple that one of them learns a subject rapidly and his or her spouse slowly. It could effect on their relation but accepting the problem and respecting to individual and personality differences could prevent marital disagreement.

Couples with different personality traits in level of programming and flexibility differ on plan and discipline. In the other hand, they differ from planning, one is very regular and deponent to plan and the other is disordered in his or her actions. The difference could cause marital disagreement. The other findings of the search is responsibility of couples, and difference in levels of responsibility, conditioning is observable during doing of works. Imbalance in conditioning and simplifying could cause marital disagreement, for example, one of couple is very responsible and conditioning in doing works on time and the other is irresponsible and inconsiderate. The difference make couple tired and increase marital conflicts, but with true management couples could act better and don't convert differences to conflicts. Latest finding of this study is difference between couple in financial and domestic management. The difference in management ability suitable distribution of duties explanation of duties and balance of financial cost and earnings in couple with differences in personality traits in management level one could manage works very good and the other obeys. One is wasteful and spend money without financial management but the other is very economic and calculator knowing these difference could prevent from conflicts.

It seems that according to the above, informing couples from their personality differences through marital skills education in method of behavioral - cognitive, marital enrichment models and third wave of behavior therapy could be beneficial and improve their integrative processes.

\section{References}

Botwin, M. D., Buss, D. M., \& Shackelford, T. K. (1997). Personality and mate preferences: Five factors in mate selection and marital satisfaction. Journal of personality, 65(1), 107-136. http://dx.doi.org/10.1111/j.1467-6494.1997.tb00531.x

Botwin, R. (2005). Humane relations psychology. Translation: Hamid Reza Sohrabi, Tehran: Roshed press.

Caughlin, J. P., Huston, T. L., \& Houts, R. M. (2000). How does personality matter in marriage? An examination of trait anxiety, interpersonal negativity, and marital satisfaction. Journal of personality and social psychology, 78(2), 326. http://dx.doi.org/10.1111/1467-6494.00049

Charania, M. R. (2006). Personality influences on marital satisfaction: An examination of actor, partner, and interaction effects (Doctoral dissertation, UNIVERSITY OF TEXAS AT ARLINGTON). 
Croyle, K. L., \& Waltz, J. (2002). Emotional awareness and couples relationship satisfaction. Journal of Marital and Family Therapy, 28(4), 435-444. http://dx.doi.org/10.1111/j.1752-0606.2002.tb00368.x

Donnellan, M. B., Assad, K. K., Robins, R. W., \& Conger, R. D. (2007). Do negative interactions mediate the effects of Negative Emotionality, Communal Positive Emotionality, and Constraint on relationship satisfaction? Journal of Social and Personal Relationships, 24(4), 557-573. http://dx.doi.org/10.1177/0265407507079249

Dyrenforth, P. S. (2010). Big five personality and relationship satisfaction: Actor, partner and similarity effects. $\mathrm{Ph} . D$. Dissertation, M chignon state University.

Etemadi, A., Navabinezhad, S. H., Ahmadi, A., Farzad, V. (2006). Evaluation of behavioral. Cognitive couple therapy effects on couples intimacy which refer to consultation canters in Isfahan. Quarterly of psychological reading, 69, 2, 87 .

Forgas, J. (1999). Psychology of social Interaction. Translation: Khashayar Beigi \& Mehrdad Phiroozbakht. Tehran: Abjad press.

Gelading, S. (2003). Family therapy. History. Theory and Application. Translations Bahari\& et al. Tehran: Tazkieh press.

Gottman, J. M. \& Levenson, R. W. (2002). Two factor model for predicting when a couple will divorce: Exploratory analysis using 14 year longitudinal data. Family Process, 14, 83-96. http://dx.doi.org/10.1111/j.1545-5300.2002.40102000083.x

Gur-Aryeh, S. M. (2010). Emotional Expressivity, Gender, and Match in personality as predictors of marital satisfaction. Phd. dissertation, Fordham University.

Jaberi, S. (2013). Determine the anticipates of marital intimacy and codify increased intimacy model according to its factors, consultation Master of Arts thesis. Faculty of Psycho logic \& Education Science University of Isfahan.

Krippendorff, K. (2004). Content analysis: an introduction to its methodology. Thousand oask, ca: sage, $162-180$.

Myers, J. (2015). The relationship of prayer and forgiveness to God attachment, romantic attachment, and relationship satisfaction in Christian married adults: A mediation study (Doctoral dissertation, Liberty University).

Olia, N., Phatehizade, M., \& Bahrami, F. (2006). Effect of marital enrichment on increasing couple intimacy. Quarterly Family studying, 134(6), 119-20.

ORourke, N., Claxton, A., Benedito, P. H., Smith, J. Z., \& Hadjistavropoulos, T. (2011). personality trait and levels within older couples and between-spouse trait differences as predictors of marital satisfaction. Aging \& Mental Health, 3(15), 344-353. http://dx.doi.org/10.1080/13607863.2010.519324

Parvin, L. (1999). Personality psychology. Translation :Mohammad Javad Javadi and Parvin kadivar, Tehran: Rasa press.

Parvizy, S., Nikbakht. A., Pornagash, S., Sharokhi, S., \& Adolescents, A. (2005). perspectives on addiction: Qualitative study. Nursing and health Sciences, 7, 192-198.

Patrick S. H., Sells, J. N., Giordano F. G., \& Tollerud, T. R. (2007). Intimacy, differentiation, and personality variables as predictors of marital satisfaction. The Family Journal, 15, 67-359. http://dx.doi.org/10.1177/1066480707303754

Pharhangi, A. (2006). Humane Relations. Tehran: Cultural Services Institute of Rasa.

Rasooli, M. (2001). Relation between Models of wife and husband relational Tehran University and Models of parent's relations. Consultation Master of Art Factually of Psycho logic university of Teacher Training.

Rastir, A. (2003). Comparing personality trails and marital satisfaction according to five factors model. Master of Art Clinical psychology. Shiraz University.

South, S. C., Krueger, R. F., Elkins, I. J., Iacono, W. G., \& McGue, M. (2016). Romantic relationship satisfaction moderates the etiology of adult personality. Behavior Genetics, 46(1), 124-142. http://dx.doi.org/10.1007/s10519-015-9767-x

Stroud, C. B., Durbin, C. E., Saigal, S. D., \& Knobloch- fedders, L. M. (2010). Normal and abnormal personality traits are associated with marital satisfaction for both men and women: An actor-partner interdependence 
model analysis. Journal of research in personality, 44, 446-477. http://dx.doi.org/10.1016/j.jrp.2010.05.011

Vater, A., \& Schröder-Abé, M. (2015). Explaining the Link Between Personality and Relationship Satisfaction: Emotion Regulation and Interpersonal Behaviour in Conflict Discussions. European Journal of Personality, 29(2), 201-215. http://dx.doi.org/10.1002/per.1993

Young, J. E., \& Long, L. (1998). Counseling and therapy for couples. New York: Guilford press.

Zoby, M. M. (2005). The Association Between personality and Marital and Relationship Outcome. Unpublished doctoral dissertation, Regent University, Virginia Beach.

\section{Copyrights}

Copyright for this article is retained by the author(s), with first publication rights granted to the journal.

This is an open-access article distributed under the terms and conditions of the Creative Commons Attribution license (http://creativecommons.org/licenses/by/3.0/). 